\title{
Et Tidsbillede i Breve.
}

\author{
Ved H. Rud, Haderslev.
}

I Aaret 1853 sejlede J. P. J u n g g r e e n, der da var 25 Aar gammel, fra Aabenraa, sammen med nogle Kammerater til Australien for at grave Guld og selv være med i Eventyrène, hans jævnaldrende oplevede paa Kysterne. Hans Helbred var ikke særlig stærkt,

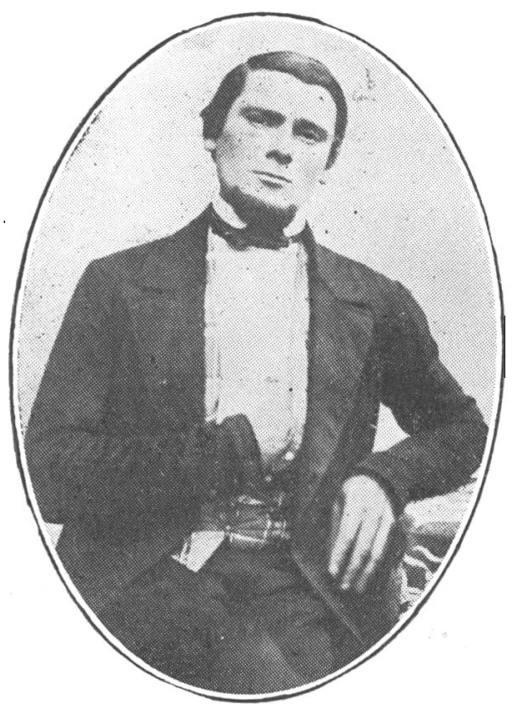

J. P. Junggreen.

og Heldet fulgte ham ikke. Efter et kortere Ophold i Australien drog han med et Skib til Kalifornien og fortsatte her Guldgraveriet, ogsaa uden større Udbytte. Han har engang mange Aar senere fortalt, at han tjente saa meget ved Guldgraveriet, at han havde et Par Aars Rejse og Ophold betalt, et smukt Guldur og en guldbeslaaet (Efter et Daurereotypi fra 50'erne.) Tobakspibe med hjem.

Junggreen var en flittig Brevskriver og førte en Del Korrespondance, men desværre er hans'Breve gaaet tabt $\left.{ }^{*}\right)$. Derimod opbevarede han selv omhyggeligt de Breve, han modtog derude, sarlig Familie-

*) Det er iøvrigt meddelt mig, at der i Haderslev Vesteramt findes en gammel Dagbog, der er ført af en ung slesvigsk Sømand paa hans Rejser Jorden rundt, bl. a. til Australien, omtrent paa samme Tid. Junggreen er nævnt heri.

H. R. 
brevene fra Aabenraa. Disse gamle Breve giver os e t Bi Ilede af Tiden i den lille sønderjydske By imellem de slesvigske Krige, og derfor aftrykker jeg enkelte af dem. Det er Dagliglivet, de handler om, - Familiens Ønske om at bevare Sønnen og Broderen for Hjemmet og Byens lille, lune Verden. Paa Baggrund af disse Breves stille Hygge lyder Frederik Fischers Kaldelse til Junggreen alvorstung og bekymret. Maaske ser Fr. Fischer allerede dengang i den unge Junggreen Arvtageren af hans egen nationalpolitiske Gerning?

BrevfraVennen Peter Christiansen (fra Enemarksgaarden ved Mønterhøj) til Mr. J am es Green, Adr. Mr. Stephens, 1 mile below the American Fork. House on the Sacramento Road.

Massachusetts flak 7. Juli 1854.

Kjære Ven!

Din lange Taushed har unægtelig foruroliget mig meget. Hver Søndag var jeg hos Posten og hos Adams, men aldrig ingen Brev fra Dig indtil den 4." Juli. Jeg vidste ikke, hvad jeg skulde tro om Din Forsvinden, men desto større var ogsaa min Glæde at se Dig i god Behold og nogenlunde tilfreds med Din nærværende Stilling. Mig er det just ikke gaaet saa godt indtil nu. Det vil sige med Fortjeneste. De første 3 Uger tjente vi just Vandet og Pikskjævlen. I den Tid gjorde jeg megen Gjeld. Men forrige Uge klarte jeg omtrent Gjelden, og denne Uge har jeg nok en 12 a 14 Dollar i Penge igen. Skulde jeg blive en Uge til, vil jeg nok kunne tjene 20 Dollar til, da vi har 
god Dyrt*).til at vaske. Men nær Ala-Bamo-Compagni begynder, saa gaaer jeg der. Det er mere sikkert og ikke saa svært Arbejde hver Dag, formedelst Vandet kan ikke naa os.

Vi arbejder til efter Solens Nedgang, og om Morgenen, veed Du nok, er jeg gjerne paa Pladsen. Jeg har skreven hiem, at vi var gaaet $i$ Compagni med en Bornholmer, at vi ikke havde tjent mere end 12 Dollars første Uge, og hvis det ikke blev bedre, vilde jeg sige digget ${ }^{* *}$ ) Farvel og gaa til Bønderne.

Sen ere Brev.

Gode Ven! Søndag efter Du forlod mig, kom der en Dansker over i Besøg og indbød os til at komme over til ham. Jeg gik gjerne med, da jeg hørte, der levede mange Danske der, for jeg haabede at faa nogen Underretning. Som jeg kom der, kom der en Mand og tiltalte mig i Løjting-Dialekt, om jeg var fra. Apenrade, nej, svarte jeg, fra Kolstrup. Hvor min Partner var fra. Fra Apenrade! Hvem han var. Jeg kendte ham ikke, hvorfor jeg nævnte Dit Navn. Men han kendte det. Det var nemlig Jeppes Bror fra Barsø. Han havde været her i 1\% Aar og tjent sig lidt, ikke betydeligt. Han vilde saa gerne tale med Dig. Han har sørget lige saa meget for at faa Dig opdaget som jeg. Han har sendt Bud til Sacramento og San Francisco for at faa Dig opspurgt, for jeg sagde, hvis Du ikke fik Beskjæftigelse, gik Du hjem, naar Du kunde træffe et Skib. Du skriver om at komme herop igen. Jeg kan i Sandhed ikke svare Dig i Dag, for sige Jo kan jeg ikke og sige Nej vil jeg ikke, da der er Mulighed for at det kunde lade sig

*) dirt, engelsk Ord for Slam.
*, o: Guldgravningen. 
gjøre. Jeg skal gjøre mere Umage i Dag, saa vil jeg' skrive Dig til. Bliv for det forste der saalænge Du kan, siden vil Du finde mig i Ala-Bamo-Compagni. Vort Telt vil Du finde paa sin gamle Plads hos Larsen. Sengene ogsaa.

Senere Brev.

\section{Gode Ven!}

Som $\mathrm{Du}$ veed, talte jeg sidst vi saaes, om at kjøbe en Clam paa Conden Baar. Jeg bød 100 Dollar for den, men til min Lykke fik jeg den ikke. De har allerede forladt den og staar til Salgs for lidet eller intet. Derimod til min Ulykke eller CaliforniaLykke kjøbte jeg en anden for 50 Dollar og kort efter en halv Sher (share). Vi kjøbte nemlig William ud, jeg og den ene Slesviger. Vi har nu arbejdet en Sluse. Vi grundsluser og ikke tjent mere end $2^{1 / 2}$ Dollar daglig. Vi havde 98 Dollar 7 Cent i 14 Dage. Det er for lidt eftersom jeg har givet for Clamen. Jeg kan vel faa mine Penge igen, men der vil ikke blive noget for mit Arbejde. Jeg spekulerer derfor paa at give diggeriet op med det første, naar jeg kunde faa en Plads til 2 Dollar om Dagen for i Vinter og siden til Sommers tjene en god Maanedshyre paa en Teglgaard.

Jeg vil fortælle Dig etEventyr, der er passeret her i Lørdags. Morschøe Wilhelm tillige med en Hollænder var i Fredags her og saa, vi havde temmelig meget Guld i Slusen. Vi gjorde just rent. Om Aftenen siger min Partner, vi maatte forvare Guldet godt, for det var for meget at miste. Jeg puttede det i en gammel Sko, hvilket var en stor Lykke for os, for da vi kom op i Lørdags fra Arbeidet, fandt vi hele Teltet overhalet, alting undersøgt, blot ikke den 
gamle Sko, saagar et af Gulvbrædderne brokken op. Mistanken faldt straks paa Wilhelm, som uden Tvivl ogsaa var skyldig. Det hele, der var borte, var en stor Dolkekniv af min Kammerats. Min Pistol lagte paa min Seng, klar $i$ Tilfældet en af os havde overrumplet ham....

Nyheder hjemmefra. Agent Bruhn gift med Jasper Thomsens Enke. Det store nye Skib, som blev bygget paa Kalø, totalt forlist paa Læssøe. Det. skulde paa England og have Kobber. Adolf satte det. Udvandringen skal være forbudt hjemme. Det er alt, jeg ved. 6 Landsmænd fra Tønder-Egnen er arriveret. her. De ser ikke ud til at kunne arbejde bedre som Du. Naar de kan, saa kan Du ogsaa. Jeg havde mere at skrive, men jeg har ingen Tid. Levvel til vi ses igen.

\section{Din Ven}

Peter Christiansen.

Brev fra J. H. Middelheus, A abenraa,") til J. P. Junggreen:

Apenrade den 29. Jan. 1855.

Gode Søn!

Dit os saa kjære Brev af 1. Dec. 54 modtoge vi for en 14 Dage siden og saae deraf, at Du Gudskelov er frisk og sund. Hvad os alle angaar, da have vi den gode Gud at takke for god Sundhed, og det gaaer os vel. Vi have til Nytaar gjort vor Skyld og God op, og

") Tobaksfabrikant og Raadmand Johan Henrik Middelheus, født 1801 i Aabenraa, var J. P. Junggreens Stedfader, gift (ca. 1830) med Henriette Junggreen, født Thomsen, fra Als. Junggreens Fader, Skibskaptajn Lorenz Junggreen døde paa en Rejse i Riga, hvor han ligger begravet.

J. H. Middelheus har i sin tyske Salmebog indført Datroerne for sine Børns Fødsel og Daab. Alle Indførsler for 1848 er sket paa Tysk, senere paa Dansk. 
Resultatet deraf viser sig Gudskelov tilfredsstillende. Vi have i sidste Aar anskaffet os nogle gode Ting, som løber i Penge, f. Ex. et Phortopiano til 220 R. R. M. 2 Speile fra Hamborg til $120 \mathrm{H}$. Courant, 12 Stole til. $100 \mathrm{H}$. Courant $\mathrm{m}$. m., og dog have vi profiteret en $2-300 \mathrm{r}$. Nu have vi faaet Tobakken 3 sR-Mønt pr. Pd. opsat. Det vil ogsaa nok hielpe noget til næste Aar. Jeg staar i Begreb med at rejse til Tønder for at afholde Auction paa Landerierne i Rutebøler Kog. Det vil være en besværlig Reise, for der er kommen megen Snee, og Veien er ikke god. Jeg har skreven Dig til, at Heinrich Andresen vil reise til Californien til Paaske, og vil reise lige til Dig. Det er nu hans Beslutning, og saa kan han fortælle Dig saa meget, men Gudskelov ikke mere end alt godt. Der kommer af og til nogle hiem fra Californien og har ikke saa lidt fortjent. Der kom for 14 Dage siden een hiem og havde i $1^{1 / 2}$ Aar fortjent sig 1000 R. Courant. Han reiste strax derhen igjen. Fra Din gode Moder skal jeg hilse Dig, at Du skal give Dig tilfreds. Lykken vil mangen Gang have Tiid. Ogsaa Moder og jeg have intet haft, og det tog længe Tiid, inden vi kunde see, at vi profiterede noget, men den gode Gud hjalp os. Giv Dig Tiid, saa vil Lykken ogsaa smile Dig til. Men for alting arbeid ikke for haardt, saa at Du kan holde det ud, og anstreng Dig ikke for meget, men giv Jer Tiid, og tag det ikke for knapt med Levnedsmidler. Lev godt, saa I kan holde det ud. Og kan $\mathrm{Du}$ indsee, at Du ikke kan fortjene noget, eller at Du hellere onsker at vil hiem, saa kan Du være forsikret paa, at Du er lige saa velkommen om Du ikke har noget. Vi skal giøre alt muligt for at sætte Dig i Gang, som det er os muligt, men for alting saa er det vort Ønske, at Du, før Du gaaer hiem, tager hen paa 
en Tobaksfabrik for at skaffe Dig Videnskab om dette Lands Fabrication og om muligt Saucen der.") Justitsraaden, Bahnsen, begge Fischers, Damm, Bähr, Hollesen, Thaning, Sørensen, J. Hansen, Løbger, Garben og alle Dine gode Venner en flittig Hilsen. Din gode Moder og alle Dine Søskende lader Dig alle hilse. Jeg har sagt til Fischer om $»$ Freja«.

Skriv os ret snart og skriv os tillige, om Du bliver saalænge, indtil Heinrich Andresen kommer. Vi have endnu vore gamle Folk paa Fabriken. Jeg maae nu slutte og ønske Dig, gode Søn, den gode Guds Velsignelse. Lev vel!

Din troe Fader

Middelheus.

Brev fra Henriette Middelh e $\mathrm{u} \mathrm{s}^{\star *}$ ) t i l J. P. J u ng g ree n (indlagt i foranstaaende Brev):

Min kjære elskede Broder!

Hvorledes gaar det Dig, kjære Jens? Naar Du vidste, hvorledes jeg og vi allesammen længes efter Dig!! Og hvor tit vi tænker paa Dig. Du vilde sikkert vende hiemad til. Du skulde være os saa velkommen. Nu seer jeg først, hvor jeg savner Dig; nu da Du er kommen saa langt bort fra os, naar Du dog barestens vilde komme. Du kan slet ikke troe, hvor vi tit ønsker Dig hiemme hos os. Vi kunde saa godt bruge Dig i denne Tid, da vi igjen skal til og spille Comedie, Du kjender vel nok det lille Stykke "Spare-

*) I et andet Brev omtales ligeledes den berømte Sauce til Skraatobak i Virginia. Junggreen hjemførte da ogsaa en Opskrift, som senere blev brugt med Held i Fabrikken. Vi hører den ogsaa omtale her af Søfolkene. Fra

$\left.{ }^{\star}{ }^{*}\right)$ Henriette Middelheus, Junggreens yngste Søster, født 1837, paa dette Tidspunkt 17 Aar gammel. 
kassen«. Vi havde allerede een Gang før villet opføre det, men den Gang gik det i Staa af den Aarsag, at vi kunde ikke faae nok Personer til at tage Deel i den. $\mathrm{Nu}$ er Hrr. Steffensen rejst til Sverrig, og veed Du, at Hrr. Helm er rejst til Norge. I hans Sted er der kommen en anden ung Herre, ved Navn Heidenheim, som er et meget vakkert ungt Menneske. Hrr. Byrresen er kommen hertil og har bragt en ung Kone med, som han hentede i Kiøbenhavn. Du kjender ham vel nok. Vi have megen Omgang med hans Kone. Og saa have vi faaet en nye Postmester, som boer hos Barensen med sin Familie. Det er en meget net Familie. Justits-Raad Lunn har bygget sig et deiligt nyt Huus. Han gjorde Bal een Gang forrige Vinter, og vi have ogsaa været til Bal paa Slottet, hvor vi morede os meget godt. Naar Du dog barestens vilde komme hiem, saa skulde vi ordentlig danse Mazurka Polka.

Moder lader mange Gange hilse, kjære Jens. Du veed jo nok, det giør hende og os allesammen saa ondt, at $\mathrm{Du}$ vil gaae derhenne og arbeide saa haardt for Dit Brød, da Du dog ligesaa godt kan ernære Dig herhiemme, kom derfor hiem, jeg beder Dig, bliv ikke for længe borte. Du kan tro, kjære Broder, at Moder sender mange varme Bønner op til den algode Gud for Dig, ja, næsten i hver Time tænker hun paa Dig. Hun beder Dig ikke at arbeide alt for haardt, men at komme ret snart hiem. Du skal bare see, hvor godt vi skal komme ud af det. Lev ret vel, kjære Jens, og Guds Velsignelse over Dig. Tænk imellem paa

Din troe Søster

Henriette. 
Brevfra Johan Middelheu $\mathrm{s}^{*}$ ) til J. P. Jung green (indlagt $i$ et af Faderens Breve).

Apenrade 14. Sept. 1854.

Min kjære høitelskede Broder.

Da Fader og Moder ogsaa tillader mig at skrive en Side til Dig saa vil jeg fortælle Dig at min Fødselsdag var den 30. August og at jeg fik et stort Kasten til at seile i Kiel med. Jeg og nogle mere af Mine Kammerader har nemlig giort os en Øe derude, Høvdinsmanden for Øen er Frederik Fischer. Doctor Gundel var engang derude, og han gav os en Mark Rigsmynt til Øens Kasse, og lovede os tillige et dansk Flag. Søndagen derefter kom vi heldigvis ned i Fischers Haver, hvor vi sat og talede lidt om et og andet og saa gik Frederik op og fik Kaffe, og jeg gik hen ved vores Kastene hvor jeg traf Nicolai Jensen, lidt efter kom Frederik og een mere og sagde at han Kl. 3 skulde hente en Kurv oppe hos Gundel og at vi KI. $3^{1 / 2}$ var parat. Da vi alle kom derud og GundeI med os sagde han at det var vel bedst at begynde med det første og, tilføjede han, nu skal I alle raaber Hurra, naar Flaget er opheist. Derpaa blev Flaget. heist og vi raabte Hurra, da det var gjort tog han en Flaske og Glasse og Kager, nu sang vi »Danmarks deilig Wand og Vænge« og da, den var tilende holdt. han en Tale, hvorpaa vi drak og raabte Hurra. Da. han paanye havde skjænkede i Glassene, sang vi igjen en Sang nemlig »Vi stod paa Codans Bølge«, nu holdt. han igjen en Tale hvorpaa vi drak og raabte Hurra.

*) Johan Middelheus, Junggreens yngste Broder, født 1842. I den føromtalte Salmebog er under den paa Tysk skrevne Optegnelse om ham tilføjet: "Han er død 20. 3. 1856«. Ovenstaaende Brev har han skrevet som 12-aarig Dreng. 
Flaaden bestaae nu af 4 Fregater og 2 Linieskibe mit er det ene af dem. Øen hedder Lyst-Øe. Nu vil jeg sige Dig farvel for dennegang og forglem ikke Din hengivne Broder.

Johan Middelheus.

Brevfra Frederik Fischer til J. P. J u ng gre e n.*)

Min kjære Ven.

For kort Tid siden kom Din Fader til mig med et Brev fra Dig, hvori Du bl. A. udtalte det Ønske, at jeg maatte sende Dig et Exemplar af min Avis. Hvor gjerne jeg vilde være efterkommet dette Dit Ønske, behøve jeg vel ikke at sige; men paa Postkontoiret svarede man mig, at der slet in te $\mathrm{t}$ A n d e t kunde sendes herfra til Californien end Breve, Pakkepostsager ikke, og uagtet jeg personlig talte med Postmesteren derom, blev det derved; han meente, at kun naar Bladet forlangtes fra England kunde det gaae, thi vi have nok en Overenskomst med England angaaende Avisers Forsendelse, men ingen med de Forenede Stater. Det er yderst kjedeligt, og jeg spekulerer endnu bestandigt paa, om der ikke kan lade sig Noget gjøre i denne Henseende. Men indtil jeg faar udtænkt nogen Udvei maa jeg renoncere paa den Fornøjelse, at sende Freja til den nye Verden. Maaske jeg gjør rigtigst i at skrive til Generalpostdirekteuren $i$ denne Sag. Jeg har lovet Din Fader selv at skrive til Dig i denne Anledning, og faaer derved tillige Leilighed til at udføre det for længe siden fattede Forsæt, at fortælle Dig lidet her hjemme fra. Jeg vil da gjøre dette, men forebigaae hvad jeg kan antage,

*) Brevet er af H. P. Hanssen offentliggjort $i$ en særlig Anledning i "Hejmdal" i Februar 1921. 
at Dine Paarørende have meldt; jeg vil navnlig holde mig til de offentlige Affairer, uanset at jeg har en vis Frygt for, at det Billede, som jeg vil afmale, vil danne en maaske stærk, men ingenlunde glædelig Modsætning til, hvad Du har hørt hjemme fra. Der er intet. Ondt i, at Din hjertesgode Faders mindre skærpede og mindre øvede Øje ikke opdager eller overseer, hvad der klart fremstiller sig for mit.

Jeg vil ikke seigpine Dig, kjære Junggreen, men jeg vil give Dig Alt paa een Gang i de Ord: vore Forventninger ere blevnesk uffede, Dine saavel som mine, om ikke $i$ alle, saa dog $i$ de fleste Henseender. Danskhedens, Nationalitetens Sol - det Centrum, hvorom dog Alt dreier sig, hvorfra ene og alene Held og Lykke udgaae - er for længe siden gaaet under, her i Slesvig i bureaukratisk Kasteaands og moderne Forsonligheds Taage, i Kongeriget i Rigdagsvrøvl og Constitutionsmanie. Det var kun i den bevægede Tid, at Embedsstanden her tilsyneladende amalgamerede sig med Borgerne, jeg kan $i$ Grnuden ikke bare mig for at lee over mig selv, at jeg kunde tro, at et saadant Forhold kunde være varigt. Efterhaanden har da ogsaa Separationen indfundet sig; Osten er skillet fra Vallen, den Ene efter den Anden er bleven opgiven af "Intelligentsen", naar ikke Embedsstilling eller - hvad mere er - Formue har vedligeholdt hans Gunst, og det mangler ikke Meget i, at Forholdene have ordnet sig, som de vare før Krigen, kun at det nu er andre Personer, der danne de afsluttede Kredse. Frederiksklubben var for simpel for de Fornemme, for fornem for de Simple. Derfor fandt den fine Verden paa at stifte en "Forening" i Stadt Hamborg, og vor Klubs sidste Time syntes at nærme sig. Imidlertid tog Bahnsen, 
Sørensen og navnlig Skrivemester Jørgensen sig af den, der blev i Vinter lavet Soireer, og Klubben har taget et saadant Opsving, at den nye Forening er nærved at falde i Staver. Embedsstanden og den fine Verden saae vi i Begyndelsen slet ikke paa vore Torsdagsaftener, de sidste Gange derimod enkeltviis. Borgemesteren har slet ikke viist sig der.

Gaae vi nu op i de højere Regioner, saa finde vi et tilsvarende System. I den allersidste Tid er en vis Springov, som i Oprøret flygtede fra Kjøbenhavn og stillede sig til Provisoriets Raadighed, bleven ansat. som Departementschef i det Holstenske Ministerium, og en vis Schulz, en dygtig Jurist vistnok, er bleven Professor i den slesvigske Lovkyndighed ved Kjøbenhavns Universitet, uagtet han har staaet som Lieutenant i Insurgenthæren. Men inden jeg siger mere om Statsforholdene maa jeg vel først anføre, at Ministeriet, bestaaende af Sponneck, General Hansen, Bluhme, Steen Bille, Ørsted, Carl Moltke og ReventlovCriminil er afgaaet tæt før Juul. Saaledes vilde det liberale Parti i Kbhvn., der kun har Sands for de saakaldte wfrie Former", det Constitutionelle, og tjener dem og dette paa præcis selvsamme Maade, som vore Schlesvigholsteinere fordums deres Tydskhed. Da f. Ex. Carl Moltke gav den tydske Fraction i vor Stænderforsamling en ganske behørig og drøj Vidsker, fordi den tog sig den Frihed at fremkomme med $\mathrm{Be}-$ stræbelser og Ytringer fra den schles.-holst. Periode, og da vi Danske her glædede os af Hjertet over, at Tydskerne havde faaet en paa Kjæften, forsikrede de liberale Blade i Kḅvn., at Al le i Slesvig, Danske som Tydske, vare i allerhøjeste Grad indignerede over Moltkes tyranniske Adfærd imod Landets Repræsentation! Og da jeg tog til Gjenmæle og 
forkyndte at alle Loyale tværtimod vare ham taknemlige og glædede sig, erklærede man i Kbhvn., Odense, Aalborg o. s. v. at et Blad, som sagde saaledes, ikke burde anses som et Organ for Folket, men var et lænkebundet Redskab af det despotiske Regimente! Da Carl Moltke senere bestemte, at vor Magistrat skulde $\mathbf{i}$ alle offentlige Udfærdigelser kalde Byen A penrade, og jeg derover udtalte min Fortrydelse, blev jeg atter sigtet for Spidsborgerlighed, fordi jeg dolerede over Navnbestemmelsen, og ikke havde revet ned paa den nye slesvigske Forfatning. Jeg fandt mig foranlediget til at skrive Apenrade paa min Avis, da jeg frygtede for, at jeg ellers kunde vente at friste samme Skjæbne som Grimm i Sønderborg, hvis Avis var standset i over et Fjerdingaar uden forudgaaet Advarsel. Saasnart altsaa Borgemesteren underskrev i offentlige Bekjendtgørelser Apenrade, satte jeg ogsaa den Form paa Bladet. Herover blev Borgemesteren mig saa fjendsk, at mit Forhold til ham er kun lidet bedre, end det var til den forrige Schow; imidlertid tror jeg nok, at mine anticonstitutionelle Yttringer, og hans forgæves Forsøg paa at faae mig til at skrive i modsat Aand, ligesaa meget er Grund til vort spændte Forhold. Jeg seer ham aldrig, men hører nok, at han ved given Lejlighed sparker ad mig. Kort sagt, kjære Junggreen, jeg maa fuldkommen sande hvad Borgemester Knudsen sagde til mig sidste Aften jeg talte med ham: "Sie werden hier noch gerade überflüssig“ - jeg er bleven det, maaskee mere end det. Imidlertid gjør dette jo intet til Sagen, naar denne kun gik frem. Men siden man i Kongeriget sætter Rigsuagsvrøvlet over Alt, selv over en fuldstændig Indlemmelse af Slesvig i Danmark - jeg vil som Beviis herfor anføre, at Or erlærer 
Sidk i Odense er bleven dygtig gjennemheglet i Bladene, fordi han, efter at have været herovre, $i$ en Forsamling opfordrede til at tænke først paa Bevaring og Forening med Slesvig, siden paa Forfatningen, siden man selv ikke i Kongeriget ænser Danskheden naar den ikke kan spændes for Liberalismens Afgudsvogn, siden man derfra behandler os akkurat paa samme hovmestrerende Maade som fordums Advokatpartiet, der jo ogsaa kaldte sig liberalt, - siden, siger jeg, har jeg ikke synderligt Haab mere om at naa Resultatet af vore Bestræbelsers Maal: Indlemmelse af Slesvig i Danmark. Vi ere blevne af̣sondrede fra Holstenerne mere end forhen, men ogsaa fra Danmark. Den nye Helstatsforfatning huer mig ikke. Den skaber et constitutionelt Kongerige Danmark, et quasiconstitutionelt Slesvig, et ditto Holsten-Lauenborg; disse tre uselvstændige Selvstændigheder ere sammenbundne ved et Rigsraad. Jeg tænker altid herved paa tre fulde Karle, som man bandt sammen med et Bælte. Springer Bæltet ved en eller anden stor Rystelse - saadan een som 1848 - saa griber Holsten-Lauenborg atter Slesvig i Nakken, og da - Godnat, Løjt Sogn!

Det hører nu ogsaa til Moden, at holde med Tydskerne, denne ædle højmodige Nation, ligeoverfor de russiske Barbarer, der undertrykke al Civilisation!! Saaledes lyde vore Frihedsmænds Sprog, og man har for Alvor tilraadet Regjeringen at slaae sig paa Vestmagternes Side og attakere Rusland! Regjeringen har imidlertid ikke været gal nok til at gjøre det, og gjør det vel eiheller saa let. Der er efter min Formening Intet, som lader frygte for, at vi skulde blive tvunget til at tage Parti, men Gud veed, hvad Tiden kan medføre, thi det seer. langvarigt ud. Vestmag- 
terne have endnu Intet, slet Intet udrettet. Den store Armada, som ifjor gik ind $\mathrm{i}$ Østersøen med saa megen Bram og Brask, har kun taget Bomarsund, en lille Fæstning paa Aalandsøerne, hvis Tilværelse er aldeles betydningsløs. Havde man før givet Kejseren af Rusland fjerde Parten af den engelske Flaades Udrustningsomkostninger, han havde vistnok gjerne selv sprængt Bomarsund i Luften derfor. Paa Krim gaaer det de Allierede værre end gudsjammerligt. Og selv om de faae Sebastopol erobret, slojfet og de derværende $10-12$ russiske Orlogsskibe brændte hvad saa, hvad have de saa opnaaet ligeoverfor Rusland, med saa enorme Opofrelser af Mennesker og Penge? Saaledes seer det ud efter at den store Kamp kan vare længe endnu, og hvad den kan medføre er skjult for Alles Øjne. Men at vi Danske skulde frivillig opgive vor Neutralitet, og af lutter Forkjærlighed for parlamentarisk Collegskab gjøre Fællesskab med hiint Land, der overfaldt os som en Røver 1807 og tiltrods for alle Garantier lod os sidde i Suppen 1848 , det haaber jeg vil aldrig skee.

Du maae, kjære Ven, undskylde, at jeg her opvarter Dig med et Sammensurium, der ikke bærer Spor af en ordentlig Fremstilling, men blander Alt. imellem hverandre. Jeg skriver under jævnlige Afbrydelser, og med muligste Benyttelse af den mig saa knap tilmaalte Tid. - Som jeg seer, har jeg forglemt at melde Dig hvem vore nye Ministre ere, og inden jeg gaaer over til det reent private, maa jeg dog nævne Dig dem. Altsaa: B a n g er Premierminister og Indenrigsminister, Udenrigsminister endnu ubesat, Oberst Lüttichau Krigsminister, Oberstlnt. Andræ Finantsminister, Prof. Hall Cultusminister, Etatsr. Simony Justitsm., Commandeur Michelsen Marinem., 
Conferentsraad Raasløf Minister for Slesvig, Geheimeconferensraad Scheel for Holsten.

Vi svæve her i en Pengecrisis, en Kamp imellem Courantmønt og Rigsbank, akkurat som i Aaret 1844, der har staaet paa i næsten et Aar og til Qual for Alle endnu ikke er til Ende. I disse Dage er Karbergs Apothek bleven lukket; Kongen har, med Hensyn til Karbergs Forhold under Oprøret ikke villet confirmere hans Privilegium. - At Kongen var her i November ifjor med sin Gemalinde, og blev ganske overordentlig feteret, veed Du vel. Iblandt Miraklerne fra hiin Tid hører, at Jørgen Paulsen, Skibsbygmester, da blev omvendt og forlod det tydske Parti, heisede Daninebrog o. s. v. Kongen var inde paa hans Plads, talte med ham, og da Paulsen skriftede og bad om Tilgivelse, blev denne ham tildeelt.

Jeg maa endelig tænke paa at slutte. I mine Privatforhold er ingen stor Forandring indtraadt. Fester er tilsøes, formodentlig nu i Calcutta, han blev conflrmeret ifjor Vinter, tillige med min Steddatter Line; næste Aar har jeg atter en til Confirmation. Katrine er hjemme, Marie ogsaa, men hun skal til Sommer ud til Petersen i Hostrup, Ludevike er hos Krüger i Bevtoft, Line hos Jes Hansen ved Nørreport. Vi ere Gud skee Lov alle friske og sunde, men Dyrtiden trykker meget haardt. I Kredsen af vore Venner er ikke forefaldet Noget, der kunde have særligt Interesse for Dig.

Kjære Junggreen, gjør nu snart Ende paa Din lange Reise og kom hjem til os, og lad Dig for Guds Skyld ikke afholde af en ugrundet Undseelse, fordi Du ikke kan komme hjem som en Krøsus. Du har samlet Erfaringer, der maaske veie mere end alt Guld, Californien gjemmer, og da her en heldbrin- 
gende Virksomhed staaer aaben for Dig, saa veed jeg ikke, hvad Du skal tøve efter. Saaledes lyder ogsaa Bahnsens og alle andre Venners Meningsyttringer.

Modtag min hjerteligste Hilsen, og skriv mig et Par Ord, hvis Du faaer Tid, men fremfor alt beslut Dig snart til Hjemreisen, for at jeg atter kan trykke Din trofaste Haand. Hvem veed, hvad Fremtiden bjerger i sit Skjød, og om ikke en trofast Sammenholden af alle Kræfter atter kan blive fornøden. Lev vel og hils Bekjendte Du muligen skulde træffe.

Aabenraa 1855 Febr. 25.

Din trofaste Fr. Fischer.

Din Fader vil, at jeg skal sende Brevet ufrankeret, da af alle hans Breve kun det ufrankerede er kommen tilstede. Henrik Andresen agter sig til Sommers over til dig, skulde jeg melde. - Vi have her en stræng Vinter, man kjører over Isen til Als.

Mellem Junggreens Breve fandt man efter hans Død et lille Vers, han har skrevet, og som viser, hvor alvorligt vort Lands Skæbne laa ham paa Sinde. Verset er uden Tidsangivelse, men det er formentlig skrevet i Tiden mellem Frederik den 7's Død og Krigens Udbrud i 1864.

Verset lyder saadan:

Tal et mandigt Ord, Kong Christian.

Lad dem ei ustraffet røve, hvad fra Fædrene vi arved.

Er i Skiæbnens Bog det skrevet,

Vi af Jorden skal udslettes, Lad det skee i Blod og Flammer.

Lad ei Danmarks gamle Rige hæderløst i Graven synke. Konge, lad os ei dø Straadød! 